\title{
Improved Mobility through Blurred Lines
}

\author{
Carol Schweiger \\ Schweiger Consulting
}

The 2010s have been the decade of innovation in transportation but it remains to be seen how successful several of the most significant innovations will be. One thing is certain: the term public transportation has a different meaning than it used to. We no longer think about traveling on individual modes; we think about the trip as a whole. We are redefining public transportation in terms of mobility rather than modes, and are concerned no longer as to whether they are operated by public or private entities. Recognizing that mobility represents an individual's travel better than specific modes will allow the transit industry to make a positive impact on travelers making trips in a manner that works best for them. One person's trip decisions will not be the same as another's.

The current transportation ecosystem includes the following services:

- Traditional fixed route public transit and paratransit/demand-response transit (DRT)

- Transportation network companies (TNCs), such as Uber and Lyft

- Micro-transit, such as Chariot

- Shared-ride services, such as Via and Localift

- Peer-to-peer carsharing/car rental, such as Turo and BlaBlaCar
- Taxis

- Carsharing, such as Zipcar and car2go

- Bikesharing, such as Capital Bikeshare (in Washington, DC) and Hubway (in Boston)

- Car rental, such as Hertz and Avis

- Autonomous (self-driving) vehicles, such as Olli and nuTonomy

In the future, all these services will be considered public transportation, assuming they are accessible to everyone. Although we do not know whether these transportation services will exist in the future, we do know that all of them have one thing in common: technology. As we look to the future of public transportation 20 to 25 years from now, technology will be one of the most critical influences.

For example, one technology-enabled innovative service that will likely be part of the future public transportation landscape is Mobility as a Service (MaaS). According to the MaaS

\section{(C) 2018 Carol Schweiger}

http//dx.doi.org/10.5038/2375-0901.21.1.7

ISSN: 1077-291X | Licenced under Creative Commons License Attribution - Noncommercial 4.0

The Journal of Public Transportation is published by the Center for Urban Transportation Research at the University of South Florida 
Alliance, "The key concept behind MaaS is to put users, both travellers and goods, at the core of transport services, offering them tailor-made mobility solutions based on their individual needs. This means that, for the first time, easy access to the most appropriate transport mode or service will be included in a bundle of flexible travel service options for end users" (MaaS Alliance 2017).

At the EuTravel Conference held in Barcelona in October 2016, four objectives of MaaS were presented (Evangelatos 2016):

- Seamless and efficient flow of information, goods, and people both locally and through long distances

- Globally scalable door-to-door mobility services without owning a car

- Better level of service than the private car

- An open ecosystem for information and services in intelligent transportation

Another key impact on public transportation is the growing number of partnerships among transit agencies and other services (e.g., transportation network companies). Almost every week in 2016 and 2017, a new partnership was formed, primarily for the purpose of either maintaining service that was underperforming and costly for traditional public transit to provide or assisting with paratransit or demand-response service. A secondary reason for these partnerships is the realization that automotive companies will be selling fewer automobiles in the future and their very existence will depend on providing alternate mobility services. Some of these partnerships will be common in 20 to 25 years.

Finally, another significant influence on the future of public transportation will be data. To date, the industry has only scratched the surface in terms of understanding and visualizing the details of how people use public transit, how they view public transit, and how well transit performs (e.g., on-time performance). Further, it is not clear yet how the future "new mobility" will affect travel behavior. We know that the millennial and centennial generations are not purchasing automobiles and instead using technology-enabled mobility options currently available. It is important to not only understand and measure the use and performance of these services going forward, but also to assess the success and influence of transit partnerships.

Transit modeling is directly related to data-driven transit. Twenty to 25 years in the future, we will have changed the existing travel models to account for the following:

- The redefinition of public transportation

- New mode choice behavior (e.g., lower car ownership, changes due to new mobility options)

- Incorporating travel incentives or rewards

- Integrating technology-enabled transportation tools

- Incorporating the effects of new transportation tools, both individually and in combination

The models will be more sophisticated in the future and will utilize the aforementioned data. 


\section{Future Technology-Influenced Transit}

While transit has deployed basic technology, in 20 to 25 years transit will be based on much more advanced technology. Four technologies will become an integral part of public transit:

1. Fully automated/autonomous transit will provide first mile/last mile (FMLM) transportation to/from fixed transit stops. While this exists today in very limited demonstrations, it will become ubiquitous. Like existing transit, it will be shared and accessible. One future feature of autonomous FMLM service is that the vehicles will be manufactured easily at low cost using 3D printers. Further, they will be capable of providing other services when not in use, such as package delivery.

2. MaaS will be the way customers obtain information about, pay for, and plan their travel. MaaS operators will be public or private entities, and will directly interact and broker services with all regional transportation service providers. Customers will be able to purchase monthly packages (from the MaaS provider) that are tailored to their transportation needs, or will be able to pay-as-you-go. Further, a customer's MaaS subscription will be usable anywhere, similar to mobile phone roaming.

3. Bots (applications that perform automated tasks) will greatly improve real-time information, which will continue to be an integral part of customer expectations and communications. Bots driven by artificial intelligence ( $\mathrm{Al}$ ) will be able to interpret a variety of real-time transit information, such as disruptions, delays, and arrival/departure predictions. This will make Real Time Information (RTI) more useful to the customer by visualizing the service interruption (e.g., in a simple route map) and by providing recommendations to avoid the problem. Currently bots are experimental-Citymapper developed a bot for New York City Transit subways - but in the future they will be used universally.

4. Blockchain protocols (along with $\mathrm{Al}$ ) that are being introduced now will become part of the fabric of the transportation ecosystem. Don and Alex Tapscott (as cited in Rosic 2017) describe the blockchain as "an incorruptible digital ledger of economic transactions that can be programmed to record not just financial transactions but virtually everything of value." According to many sources, including Ernst \& Young and Blue Phoenix Inc., the mobility experience will evolve into a truly cognitive and interactive experience due to an open-source distributed ecosystem built on a blockchain protocol (Licata 2017). Further, blockchain will "allow riders to not only safely take a ride to or from, it will be an application used to help consumers be more integrated into their communities" (Licata 2017). Finally, an integrated mobility platform underpinned by blockchain technology such as Tesseract, recently launched by Ernst \& Young, will facilitate "fractional vehicle ownership, shared use and seamless multimodal transport, and will provide access to a variety of on-demand mobility options" (AftermarketNews 2017).

\section{Future Transit Partnerships}

With the advent of autonomous vehicles, individuals no longer needing to own vehicles, and MaaS becoming commonplace, in 20 to 25 years transit will become much more prominent in our society. However, it will not be able to operate the way it does today. Transit agencies 
will have to team with a variety of other transportation companies and services to provide effective and efficient on-demand transportation. This is where the lines that exist today among public and private "transit" services will become blurred.

There has been considerable speculation as to the success of current services and service providers, but their viability will most certainly affect these future partnerships. Since we cannot predict the viability of the various providers, assessing current partnerships among transit agencies and other service providers in the U.S. Department of Transportation's Mobility on Demand (MOD) program, as well as other recently announced partnerships, can give us some visibility into the future of partnerships. For example, the Regional Transportation Authority of Pima County, Arizona, is teaming with Metropia, which provides technology to streamline and incentivize social carpooling, and RubyRide, a subscriptionbased personalized driver service, to enhance mobility access to work and various life needs for citizens needing or wishing to reduce car dependency. The overall goal of this partnership is to "transform the existing fixed-route transit system, improve overall system reliability and efficiency, and increase ridership while delivering a seamless user experience" (Regional Transportation Authority of Pima County 2017).

The key elements of this MOD project are what will result from this type of partnership in the future: "integrated systems, and an innovative business and operation model that operate in concert to bring affordable services to a wide range of demographics" (Regional Transportation Authority of Pima County 2017).

Another example of a partnership with public transit that will likely exist in the future is a technology vendor working with a transit agency to have the agency provide on-demand service rather than have it provided by a service contractor, which is most prevalent today. For example, a recent partnership between a technology vendor and a transit agency resulted in creating a better flexible/on-demand service using simulation, data analysis, and other techniques. This is a significant departure from current relationships between transit agencies and technology vendors, which are somewhat superficial; the vendor installs software and/or hardware, but rarely gets involved in the agency's operations and planning.

Future partnerships between transit agencies and other service providers will incorporate the following elements (Transportation Research Board 2017):

- Benefits and outcomes, both quantitative and qualitative, that public transit agencies, other service providers, communities, and riders can expect from the partnership must be identified

- Challenges that will be faced by the stakeholders as a result of the partnership must be identified, as well as strategies for mitigating risks, through a detailed risk assessment

- The partnership agreement must describe requirements for the services delivered, data sharing, ridership incentives, passenger payment methods, financial arrangements, and workforce requirements and relationships

- Methods and metrics for measuring outcomes of the partnership must be identified; these could include measuring transit ridership, mode share, and impacts on finances, congestion, and customers

- Mechanisms for accountability of the partner(s) must be identified 


\section{Future Data-Driven Transit}

Only recently have transit agencies discovered the value of data-both the data they provide to the public (open data) and the data generated by transit technology (e.g., automatic vehicle location). Agencies have been turning the latter into traveler information for their customers (e.g., real-time information). In the future, this data will be combined with many other types of data, including non-transit travel data, so that the agency can determine what services are needed by customers and what services should be modified, expanded, or eliminated.

We can expect that transit agencies in 20 to 25 years will integrate the data listed in Table 1 below on a routine basis to improve mobility.

\section{TABLE 1.}

Future Transit Integration

\begin{tabular}{|c|c|}
\hline Data & Example \\
\hline \multicolumn{2}{|l|}{ Transit timetables } \\
\hline Real-time transportation information & $\begin{array}{l}\text { Real-time transit vehicle location, next transit vehicle arrival/departure, } \\
\text { real-time passenger counts by location, incident information, and } \\
\text { traffic flow/congestion information }\end{array}$ \\
\hline $\begin{array}{l}\text { Transit performance metrics, } \\
\text { historical and real-time }\end{array}$ & $\begin{array}{l}\text { On-time performance, ridership (e.g., number of boardings/alightings } \\
\text { by location) }\end{array}$ \\
\hline Transit reliability & $\begin{array}{l}\text { Percent of customers who waited less than the scheduled time } \\
\text { between vehicles, percent of vehicles that arrived at their final } \\
\text { destination no more than a certain amount of time after they were } \\
\text { scheduled to arrive, a vehicle departing no more than a certain } \\
\text { amount of time later than the expected interval between vehicles }\end{array}$ \\
\hline Transit customer satisfaction & $\begin{array}{l}\text { Overall satisfaction, likelihood of continuing to use transit, likelihood } \\
\text { of recommending transit, and perception of transit reliability }\end{array}$ \\
\hline Transit route characteristics & Geometry \\
\hline $\begin{array}{l}\text { Transit stop/station characteristics, } \\
\text { both static and dynamic }\end{array}$ & Amenities (static) and Real-time Passenger Flow (dynamic) \\
\hline Multimodal journey planning results & $\begin{array}{l}\text { Results of trip planning via Google directions for driving, transit, } \\
\text { cycling, and walking }\end{array}$ \\
\hline $\begin{array}{l}\text { Social media/network mapping } \\
\text { regarding transportation }\end{array}$ & Tweets about service interruptions \\
\hline $\begin{array}{l}\text { Transport-sharing usage, both real- } \\
\text { time and historical }\end{array}$ & Bikeshare, carshare, taxi, and TNCs origins and destinations, and usage \\
\hline Transportation payments & Fare, toll, and congestion payment amounts and locations \\
\hline $\begin{array}{l}\text { Travel behavior data, both } \\
\text { quantitative and qualitative }\end{array}$ & Survey results \\
\hline Parking data & Real-time and historical capacity \\
\hline $\begin{array}{l}\text { Package delivery data, both real-time } \\
\text { and historical }\end{array}$ & Package delivery times and locations \\
\hline
\end{tabular}


The integration and analysis of these data in the future assumes that transportation data generated by the transit agencies in a region shall be open. The open nature of this data will result in more opportunities for analysis and visualization, since individuals and entities beyond the public sector will conduct their own analyses for various reasons. This future data state will rely on some service providers opening data that is currently not available to the public, such as operational data from TNCs.

Hand-in-hand with transit being data-driven in the future is the need for new models to account for the aforementioned future partnerships and preponderance of on-demand transit. Currently, many of the models that predict and help plan for future transportation are old and have not been updated to reflect the key factors that affect mobility. For example, most models do not account for the shift in travel decision making and behavior, particularly by millennials and centennials; new transportation providers, such as TNCs and autonomous vehicles; shifting away from car ownership; the effects of new schemes, such Mobility as a Service; and changes in land use. In 20 to 25 years, new transportation models that incorporate the aforementioned data will be commonplace.

\section{So What Will Future Transit Be?}

Based on the three major influences on transit described in this paper-technology, partnerships, and data-we can expect that transit will become much more flexible and technology-enabled, providing more on-demand service and partnering more with transportation service providers who can augment basic transit services in a cost-effective manner to meet customers' needs. Transit agencies could be MaaS companies as well. Better modeling that accounts for the effects of available transportation services, demographic trends, and travel patterns will be used to develop new transit services.

While this paper does not explicitly discuss the ongoing need for transit that is fully accessible and equitable in the future, all future transit services must be accessible to all, regardless of income level, mental or physical ability, age, or location. And even though transit will be more technology-enabled, individuals who do not have access to the technology will be able to access transit service through manual means.

The bottom line is that transit will improve mobility in the future by being much smarter, more personalized, and more nimble.

\section{References}

AftermarketNews. 2017. EY Advancing Future Of Transportation With Launch Of BlockchainBased Integrated Mobility Platform. Babcox Media, Inc. Retrieved from http://www. aftermarketnews.com/ey-advancing-future-transportation-launch-blockchain-basedintegrated-mobility-platform/

Evangelatos, S. 2016. "Mobility as a Service (MaaS) - Concept and Landscape." Presentation by Inlecom Systems at EuTravel Conference. Retrieved from http://eutravel.eu/Conference/ wp-content/uploads/2016/10/INLECOM_EUTRAVEL.pdf 
Licata, J. 2017. How blockchain will transcend how Al is used in mobile transportation. Hacker Noon. Retrieved from https://hackernoon.com/how-blockchain-will-transcend-how-ai-isused-in-mobile-transportation-e9961e78fb94

MaaS Alliance. 2017. The European Mobility-as-a-Service Alliance. Retrieved from https://maasalliance.eu/european-mobility-service-alliance/

Regional Transportation Authority of Pima County. 2017. Adaptive Mobility with Reliability and Efficiency (AMORE) - Rita Ranch Area Pilot in Tucson, Arizona. Mobility on Demand (MOD) Sandbox Summary. https://www.transit.dot.gov/sites/fta.dot.gov/files/FTA\%20 MOD\%20Project\%20Description\%20-\%20Pima\%20County.pdf

Rosic, A. 2017. What is Blockchain Technology? A Step-by-Step Guide For Beginners. Blockgeeks. Retrieved from https://blockgeeks.com/guides/what-is-blockchain-technology/

Transportation Research Board. 2017. "Collaborations and Partnerships between Public Transportation and Transportation Network Companies (TNCs)." TCRP J-11/Task 26 Request for Proposals. Retrieved from http://apps.trb.org/cmsfeed/TRBNetProjectDisplay. asp?ProjectID=4297

\section{About the Author}

CAROL SCHWEIGER, president of Schweiger Consulting, has more than 37 years of experience and is recognized nationally and internationally in transportation technology consulting. Her expertise covers a wide range of specialty areas including systems engineering, technology strategies for public agencies, public transit technology, and traveler information strategies and systems. Ms. Schweiger co-developed and was the lead instructor for five transit technology training courses for the National Transit Institute (NTI). Further, she developed and delivered (via webinar) six modules regarding transit technology standards. She has authored numerous Transit Cooperative Research Program (TCRP) Synthesis reports and full TCRP reports. 